\title{
Toward Theoretical Inclusiveness in Clinical Social Work
}

\author{
Leslie Cummins ${ }^{1,2}$
}

Published online: 8 November 2017

(c) Springer Science+Business Media, LLC 2017

Bruce Thyer brings up an important issue in his paper, "It is Time to Delink Psychodynamic Theory for the Definition of Clinical Social Work." (Thyer 2015). The title of his paper gets at the perennial question of social work: What defines us? Although Thyer agrees with the NASW's and Social Work Dictionary's emphasis on the role of clinical social work as addressing emotional and mental disorders, he rightly touches upon the vagueness of that definition with which our professions struggles. No one technique is specified for service provision, allowing for many approaches to mental and behavioral health. Further supporting Thyer's allegation that the current definition needs refining, it is worth noting that the NASW, in its many online subheadings under clinical social work, omits "mental health," but does include "behavioral health." And, although Thyer's reasoning for delinking psychodynamic theory from the definition of clinical social work is thought-provoking and worth debating, I will counter that his recommendation is based on faulty reasoning and, ultimately, is the wrong one.

Thyer proposes that the NASW's specifying psychodynamic theory in its standards constitutes "privileging of one form of theoretical knowledge over another [and] is unjustified, and reflects a socially unjust exercise of empowerment of one element of the profession over another." $\mathrm{He}$ enumerates three instances in which he states this is the case: in Standard 2 of the NASW Standards for Clinical Social Work; in the description of criteria for the Qualified

Leslie Cummins

leslie.cummins@nyumc.org

1 Institute for Psychoanalytic Education, 1 Park Ave, New York, NY 10016, USA

2 Metropolitan Institute for Training in Psychoanalytic Psychotherapy, 160 W 86th St, New York, NY 10024, USA
Clinical Social Worker (QCSW); and on the application for the Diplomate in Clinical Social Work, a title endorsed by the NASW. Thyer states that his aim in this paper is not to elevate any one theory over another, but is to "advocate on behalf of all clinical social workers who do not make use of psychodynamic theory... Such persons are legion, far outnumbering those who retain the psychodynamic framework." (Supporting data of these statements would be helpful). He lists the many frameworks which inform contemporary practice, and even writes, "The history of science is replete with examples of officially-endorsed theories being harmful (my italics) to progress."

One could take issue merely with Thyer's characterizations of the definitions he opposes. His citation of the Standards paragraph: "Drawing upon knowledge of systems theory, person-in-environment orientation, psychodynamic theory, interpersonal dynamics and family systems," requires the working knowledge of several constructs, belying his statement that inclusion of psychodynamic theory by the NASW is "epistemological elitism, a privileging of one category of knowledge over another." Thyer's quote from the application for the Diplomate, "Clinical social work centers on a holistic approach to psychotherapy and views the client's relationship with his or her environment as essential to treatment planning and includes interventions directed to interpersonal interactions, intrapsychic dynamics, and the support and management of life issues" (emphasis added). This definition includes these interventions, it does not dictate their use. Thyer's argument would also be strengthened considerably by including supporting data of statements such as, "Such persons are legion, far outnumbering those who maintain the psychodynamic framework;" "One of the more popular practice models... is Solution-Focused Brief Therapy;" "the majority of practitioners no longer utilize that theory," and so on. 
Putting these semantic and rhetorical quibbles aside, I would like to indicate several erroneous premises for Thyer's proposal for removing "psychodynamic theory" from NASW guidelines (and, therefore, one presumes from social work education). Firstly, although it is true many current treatments contain elements of theories borrowed from other disciplines, his citation of the inclusion of chaos theory, cybernetics, and other "conceptual frameworks" in Turner's 2011 textbook is questionable, given that these are not theories of human behavior. Most would not characterize any of Thyer's referenced frameworks as psychological theories; they offer useful ways of thinking or models, but they do not explain human behavior. Chaos theory, cybernetics, and even communications systems theory replace neither psychodynamic nor learning theory - they add to existing knowledge, when best utilized; when least, they substitute metaphor for understanding. However, just as a description of behaviors does not reveal etiology, neither does the description of systems of communication explain psychological theory.

The related error is a categorical one: Thyer conflates theory and technique. Many techniques can cite supportive data, but not do not necessarily explain how or why they work. There is ample evidence of the efficacy of myriad approaches today, but technique doesn't equal a theory of mind or behavior. In fact, one might categorize all techniques as arising from one of psychology's original theories: cognitive-behavioral (such as cognitive processing therapies, ACT, DBT, prolonged exposure therapy, etc.) and psychodynamic (attachment, relational, intersubjective, shortterm psychodynamic psychotherapy, transference-focused therapy, etc.). These approaches, and many others, stand upon journals filled with statistical evidence, but technique and theory are not equivalent-interactional, perhaps, but not interchangeable.

These assertions beg the implicit question in Thyer's paper: why attribute importance to any theory in clinical social work's definition? This is a question posed of Thyer and Barbara Levy Simon in 1994 (Thyer 1994). Although he rejects the label of "anti-theoretician" in that response, Thyer seems here to propose that technique doesn't actually require a knowledge of theory; in other words, it may not be necessary to understand why a treatment works, just that it does. Theory is critical to understanding, evaluating, and building approaches. Relying for treatment and/or education solely on quantitative data measuring effectiveness of manualized treatments is specious. As Simon (1994) writes in her opposing response cited above, "method-driven social work that is cut off from theoretical moorings is at considerable risk of taking on a life of its own, of becoming methodcentered rather than client-centered." Clinical social work betrays its own stated mission when it becomes founded on manualized protocols rather than the intra- and interpsychic relationship of individuals to their world.
Conceptual knowledge is crucial to conviction, creativity, and even ethics, regardless of the applied approach. The therapist's belief in method rests upon theoretical understanding, not merely technical acumen. Cameron (2014), among others, cites much research supporting that the shared interpersonal characteristics of all approaches provide the actual mechanisms of change. These "common factors" are the establishment of trust; empathy and its genuine delivery; the provider's hopefulness; as well as the client's abilities and support system. Implicit in the provider's optimism is, Cameron (2014) states, "that whatever approach practitioners use, the extent to which they believe in the effectiveness of their approach and convey this to clients promotes... the power of the work" (p. 152). These common factors are characteristics of attachment and relational theory, which themselves arise from psychodynamic theory. Theoretical conviction is essential to good treatment. This thinking is not limited to interpersonal theory. Abramowitz (2013), writing about exposure therapy, advocates for the centrality of theory for the practitioner, as it helps in treatment planning, interventions, and assessment. For this writer, a firm foundation in learning theory promotes clinician belief which in turn promotes a better client-patient relationship, providing the environment for effective exposure therapy and better outcomes.

It is doubtful even the strictest behaviorist would deny that any type of psychotherapy is best conducted with a creative and supple mind (or perhaps minds). But, like any best application, artistic or scientific, creativity must be practiced within the confines of form; it is only through theoretical understanding that flexibility can be achieved and new technical iterations created. Psychotherapy is not solely a "scientific" method; it requires art in its collaborative approach, requiring close attention to the interaction as well as the client's response. The dancer and choreographer Martha Graham (in Heil 2016) could just as well be discussing therapeutic technique as well as dance technique when she states: "My only fear is always with people who decide they want to begin with what I would call creativity... instead of permitting themselves to go away from tradition after having a thorough knowledge of what one is going away from" (p. 124). Heil further interprets Graham, writing that "dance, like any academic discipline, passes on established knowledge, explores unknown avenues, and develops new practices" (p. 123). Therapeutic solutions and change result from flexibility and creativity based in foundational learning.

And, what of ethics? Without theoretical understanding, straying into ethical problems can become more likely. Clinical social work reflects values, and an essential one is the individuality of the client. The relation to theory can provide the objectivity necessary for effective therapy, as well as to clarify client-provider boundaries. Knowledge of theories of relationship, integral to any approach, strengthens the 
practitioner's beliefs, minimizing the chance of violations of boundary and technique that can occur. As stated by Hutchinson and Oltedal (2014), "Ethical reflection is important in social work... In social work, it is not enough to behave critically or be reflective about the situation. Social workers have to be considerate of the people they are dealing with face to face" (p. 7). Ethics are based in values, and values are established through shared concepts, not merely methodology.

Thyer omits another essential point: no technique is pure. It is difficult to imagine any practitioner not, even unwittingly, incorporating techniques outside of one's professed model of practice. Psychoanalytic ideas pervade clinical, even popular, thinking. It is doubtful that any modern practitioner does not utilize many lines of thinking when working with or diagnosing clients. A practitioner utilizing technique based on amateur theoretical understanding may be worse than no technique at all. Further, one must understand theory even if only to reject it; outright dismissal is not an intelligent approach. The defining object of social work theory, the "person in environment," demands that we examine all the aspects of a person's internal and external life. Despite declaring that his paper doesn't value any theory more than another, Thyer leaves the reader with the impression of an implicit dismissal of psychodynamic constructs. It is hard not to hear the criticism of psychodynamic therapy as outmoded when he writes, “... the official linkage of clinical social worker can be seen as an historic anomaly and one that should be corrected to reflect the evolution in our field."

This is erroneous given the burgeoning evidence for psychodynamic psychotherapies. Since Shedler's (2010) wellknown paper describing several meta-analyses of random control trials showing significant effect sizes of psychodynamic psychotherapy, numerous studies have provided additional support. The numbers are even more impressive when measured across time, with well-documented benefits greater than those from behavioral techniques. More studies exist supporting psychodynamic psychotherapy's greater benefit for personality and complex disorders (see the British Psychoanalytic Council for a comprehensive aggregation of studies). Further, the long-term effects of psychodynamic psychotherapy show significant promise over manualized treatments. Yakeley and Hobson (2013) cite many studies corroborating the advantages of long-term psychodynamic psychotherapy for particular conditions, such as depression, panic disorders, and somatic disorders, and its cost-effectiveness in co-morbid disorders and reduced service usage. Midgley and Kennedy (2011) document 34 studies supporting psychodynamic psychotherapy for children and adolescents. Town et al. (2011) have provided evidence supporting Davanloo's use of "unlocking the unconscious" in Intensive Short-Term Psychodynamic Psychotherapy as more effective than not accessing unconscious material. Attachment-based therapies have been utilized successfully in many diagnostic categories including autism, borderline personality disorder, and treatment-resistant anxiety (Milrod et al. 2016), as well as receiving support from neuroscientific research. What happens when the "answer" does not lie in the "(c)lient's learning history," a la Thyer, when co-morbid conditions exist and/or when serious personality disorders are present? Recent research suggests that long-term psychodynamic psychotherapy may be the most effective treatment in these complex cases.

Finally, but not least, I would counter Thyer's implicit suggestion that technique is ahistorical. In order to move forward, history needs to be taught. Knowing the history of clinical theory and its contexts are essential to identifying and defining clinical social work. As practitioners, we should understand both the limits and possibilities of the theory underlying our historical evolution. Theoretical and intellectual history inform our growth as a profession. Many masters-level social workers seek specialized training following graduate school; learning the foundations allows them to make informed choices about which path to follow based upon theory they find most useful, and why. Thyer's thinly-veiled charge, "The history of science is replete with examples of officially-endorsed theories being harmful to progress" (my italics) is controversial at best. The new should not be confused with progress and the old with the disproven. For an example of this, one need look no further than CBT, which recently has been somewhat supplanted by Acceptance and Commitment Therapy.

Thyer's suggestion can be discounted in total if clinical social work is to forge a path forward not only for our professional definition, but also for best treatments for all populations. As delineated by McWilliams (2017), "The hazards of the mental health scene today are not so much arrogant, antiresearch attitudes and orientation rigidity as industrialization, destruction of relationship, indifference to research on relational and nonverbal aspects of therapy, and wholesale denial of psychological treatments for people with very serious pathology" (p. 292). The proposition that clinical social work should eliminate one of our primary identifications is an unfortunate one.

Social work's clinical history begins with Freud. Psychodynamic theory and technique have been more the province of social work, while the field of psychology incorporated more readily cognitive-behavioral theory, and psychiatry has been based on a biological model. As Thyer points out, clinical social workers are licensed to perform more tasks than ever. Holistic thinking and practice are foundational to social work. Proposing that the NASW's criteria shouldn't specify psychodynamic theory, Thyer risks simplifying social work's mission. That new definition would, ironically, relegate our profession to an even smaller position by supporting the premise that social work treatment addresses symptoms only. In fact, contemporary social workers are 
uniquely qualified to consider many various models when evaluating, treating, counseling, and consulting. Thyer is correct in stating that clinical social workers currently enjoy more privileges, but this is an argument for more theoretical knowledge, not less.

These points lead to a different recommendation: The guidelines for clinical social work should include learning and behavioral models, but not omit psychodynamic theory. After all, even Skinner acknowledged the value of some Freudian ideas, including dream symbolism and defense mechanisms. Although Skinner characterized his technique as vastly different from Freud's, his attempt at undergoing his own psychoanalysis portrays a tacit acceptance of Freudian theory (Overskeid 2007). It is interesting to note that the many historical criticisms of clinical social work's ready adaptation of psychoanalysis have been forgotten in the current climate of our unquestioning acceptance of evidence-based practice. Perhaps it is a fear of being left out of governmentally-supported payment scales which has once again allowed social work to let other professions define us rather than stake our claim as the profession that best bridges the psychological-psychiatric divide.

I will conclude with two anecdotal examples which I believe support a statement of inclusion: I am a clinical social worker, trained in psychodynamic therapy and psychoanalysis. After many years of practice, I enrolled in a doctoral program that exposes me to current techniques that may supplement my care and offer differing theoretical perspectives. I may not go on to master any of these techniques, but I now have a more thorough understanding of their underlying theory and uses, and can therefore evaluate them more effectively. Knowing these approaches not only enlarges my repertoire, it fulfills the basic social work tenet of providing the best care, allowing me to make informed referrals, and may solidify or augment my psychoanalytic conviction. Conversely, in my capacity as a psychodynamic supervisor and teacher, I have come across many students (as well as clients) who have felt that the cognitive-behavioral model was not an adequate explanation of what they came to know clinically, or satisfied their own curiosity about depth psychology or structural change. Thyer's proposal opens an important dialogue about social work identity. His paper highlights issues that warrant continued examination. But the answer is not either/or, but and.

\section{References}

Abramowitz, J. (2013). The practice of exposure therapy: Relevance of cognitive-behavioral theory and extinction theory. Behavior Therapy, 44, 548-558.

British Psychoanalytic Council. (n.d.). Psychoanalytic psychotherapy: What's the evidence? http://www.bpc.org.uk.

Cameron, M. (2014). This is common factors. Clinical Social Work Journal, 42, 151-160.

Heil, J. (2016). Exercises in discipline and freedom? The Graham Technique. Dance Chronicle, 39(2), 123-152.

Hutchinson, G. S., \& Oltedal, S. (2014). Five theories in social work. UiN-report, Universitetet i Nordlund. http://www.uin.no.

McWilliams, N. (2017). Integrative research for integrative practice: A plea for respectful collaboration across clinician and research roles. Journal of Psychotherapy Integration, 27(3), 283-294.

Midgley, N., \& Kennedy, E. (2011). Psychodynamic psychotherapy for children and adolescents: A critical review of the evidence base. Journal of Child Psychotherapy, 37(3), 232-260.

Milrod, B., Chambless, D. L., Gallop, R., Busch, F. N., Schwalberg, M., et al. (2016). Psychotherapies for panic disorder: A tale of two sites. The Journal of Clinical Psychiatry, 77(7), 927-935.

Overskeid, G. (2007). Looking for Skinner and finding Freud. American Psychologist, 62(6), 590-595.

Shedler, J. (2010). The efficacy of psychodynamic psychotherapy. American Psychologist, 65, 98-109.

Simon, B. L. (1994). Are theories for practice necessary? Yes! Journal of Social Work Education, 30(2), 144-148.

Thyer, B. (1994). Are theories for practice necessary? No! Journal of Social Work Education, 30(2), 148-151.

Thyer, B. (March 20, 2015). It is time to delink psychodynamic theory for the definition of clinical social work. Clinical Social Work Journal Online.

Town, J. M., Abbass, A., \& Hardy, G. (2011). Short-term psychodynamic psychotherapy for personality disorders: A critical review of randomized controlled trials. Journal of Personality disorders, 25(6), 723-740.

Yakeley, J., \& Hobson, P. (2013). Evidence in support of psychodynamic psychotherapy. http://www.iaap.org.

Leslie Cummins Faculty, Institute for Psychoanalytic Education, New York University School of Medicine, Metropolitan Institute for Training in Psychoanalytic Psychotherapy. 